\title{
Aggressiveness and ethnic intolerance as factors of extremist behavior
}

\author{
Kyuri Idrisov ${ }^{1, *}$, Islam Khazhuev ${ }^{1}$ and Aslanbek Saidov ${ }^{1}$ \\ ${ }^{1}$ Chechen State Pedagogical University and Chechen State University, 364068, Grozny, Russia
}

\begin{abstract}
The article presents the results of a study of the relationship between aggressive behavior of an individual with the parameters of socioethnic intolerance and socio-psychological attitudes in the motivationalneed-sphere of the individual, in the context of experiencing intense stress caused by a traumatic event. The study involved 118 people - representatives of the youth of the Chechen Republic in the age range from 18 to 25 years. The results of the study showed that aggressive forms of behavior are accompanied by an increase in the general level of social intolerance, which is one of the significant factors in the growth of tension in society, since the manifestation of disrespect and intolerance towards others in the context of interethnic and interfaith interaction is accompanied not only by the growth of conflict situations in society, but also provokes extremist ideas and forms of behavior. At the same time, certain forms of aggressive behavior tend to intensify when the individual experiences situations of a psycho-traumatic nature, associated with the development of intense stress reactions.
\end{abstract}

\section{Introduction}

The problem of extremism in recent decades has been relevant both for individual countries and regions of the world. As various authors point out, this is due primarily to the growth of political activity of various public organizations, associations and groups of the population. Moreover, the spectrum of this activity is quite wide and manifests itself both in political hooliganism (insulting representatives of the authorities, unauthorized holding of meetings, pickets, putting inscriptions of a political nature, etc.), and in political killings, hostage-taking, the activities of various terrorist organizations [1].

The growth of extremism in society is preceded by economic and social crises in the country, disasters and impoverishment of the population, gross violations of democratic rights and freedoms, authoritarianism, totalitarianism, fascism, etc. In addition, according to O. A. Rusanov [2] the development of extremist tensions in society is facilitated by interethnic and intercivilizational conflicts. According to S. N. Fridinsky: “... the extremist movement is a complex phenomenon. Its appearance is due to the presence of a number of factors closely interacting with each other. The most important of them are: economic, sociopolitical and ideological" [3]. According to M.K. Archkov, this classification is not complete, since it does not consider psychological (motivational), cultural and religious reasons that contribute to the emergence and development of extremist activity [1].

\footnotetext{
* Corresponding author: kyuri.idrisov@yandex.ru
} 
The origins of extremism and terrorism, which are manifested in the violent actions of a small group of aggressive people against the majority of the population, lie in specific sociopsychological phenomena. These phenomena, forming the psychological basis of intolerant interethnic, interfaith, and race relations, are based on the unconscious division of people into "friends "and" foes " - different in appearance, different in behavior, and different in views and values. In this regard, intolerance manifests itself in intolerance in human relationships and behavior when interacting with other people on the basis of a wide variety of signs. And the obvious manifestations of intolerant behavior include discrimination, xenophobia, extremism and terrorism [4].

At the personal level, the preconditions for extremism can be caused by the deterioration of social status and financial situation. When the gap between the individual's claims and the possibilities of satisfying them increases, aggressive attitudes increase. Social dissatisfaction often (and usually) leads to the search for an "enemy", which is either the government, or some competitive groups, representatives of other nations or other religions. Such a state of personality caused by difficulties its social or cultural self-determination is designated by the term "identity crisis". All this, in turn, contributes to the split of society on the principle of "we - they", "friends - foes" [5].

A significant role in the growth of extremism and xenophobia is played by the growth of aggressive attitudes in society. And the increased aggressiveness of individual members of society, due to various socio-psychological and individual-personal crises (prolonged deprivation and frustration, experiencing traumatic situations, systematic violence in childhood, etc.), as indicated by literary sources, can be sublimated in the context of xenophobic and extremist activities. It should be noted that the aggressiveness of the individual is understood (in the works of psychoanalysts and biologists) as an innate form of hostility towards the outside world. According to the theoretical concepts of representatives of depth psychology (psychodynamic), which reveal the nature of aggression, the aggressive instinct is initially directed towards the outside world. The lack of an individual's ability to discharge it, internalizes the energy of aggression, causing the development of various destructions. At the same time, in the psychoanalytic environment, there is also an opinion that aggression is not an instinctive formation, but a personality's reaction to certain influences of the surrounding world, mainly hostile and, accordingly, provoking aggressive reactions in the individual $[6,7,8]$.

At the same time, the leading domestic authors and researchers oppose the aggressiveness of the individual, the susceptibility of his xenophobia and violence to the general culture of society's tolerance, which is the basis of the socio-psychological stability of the individual to the diversity of the world, to ethnic, cultural, social and ideological differences of people [1].

That is why in Russia, at the state level, there is a special urgency of purposeful work on the formation of tolerance among citizens and the elimination of any manifestations of xenophobia. This activity is aimed at preventing, detecting and suppressing interethnic conflicts and extremist activities [9].

Theoretical and practical aspects of tolerance are actively discussed in the scientific discourse (the works of L. M. Buldygina, N. I. Vilkhovskaya, N. S. Gadzhigasanova, E. V. Krivtsova, p. R. Koval and others are of Research interest). Experts consider its essence from various methodological positions in the framework of philosophy and cultural studies (Zh. b. Ryzhova), sociology and political science (I. I. Demidova, P. V. Masychev, A.V. Mozgovaya and others), psychology and pedagogy (T. P. Dneprova, F. V. khugaeva, S. B. Fadeev) [10].

Despite the fact that the definition of "tolerance" is identified by many researchers with the concept of "patience", it should be noted that the term "tolerance" does not mean passive conquest of the opinion and actions of other subjects of activity, but an active moral position and psychological readiness for tolerance. the purpose of positive interaction with people of a different culture, nationality, religion or social environment [11, 12]. According to L.M. 
Dorbizheva, tolerance is: “... the readiness to accept others as they are, and to interact with them on the basis of understanding and agreement" [13]. In the context of all of the above, one of the main types of tolerance is ethnic tolerance, which serves as the basis for the development of interethnic relations and cooperation between representatives of different cultures, especially in such a multinational and multi-confessional country like Russia.

However, many theoretical and practical issues of the state of ethnic tolerance among the peoples of the North Caucasus in general, and in the Chechen Republic in particular, remain poorly studied, which required a special study, the purpose of which was to identify the relationship between aggressive reactions of a person with low ethnic tolerance and sociopsychological attitudes in motivational the need-related sphere, as factors determining the formation of extremist ideas and forms of behavior in the context of traumatic experiences of the individual..

\section{Materials and methods}

The sample included 118 people, students from various higher educational institutions of the Chechen Republic, aged 18 to 25 years. The criteria for inclusion in the sample were voluntary consent on anonymous terms.

The following methods were used as diagnostic standards: the scale for assessing the impact of a traumatic event [14]; the index of ethnic tolerance [15]; the questionnaire "Aggressive behavior" by P. A. Kovalev [16]; the "questionnaire on the level of xenophobia" (E. N. Yurasova) [17]; Diagnostics of socio-psychological attitudes of the individual (Potemkina test) [18].

For statistical processing of the data obtained, the following were used: Pearson's chisquared test ( $\square 2$ ) to identify and evaluate paired relationships; Spearman's rank correlation coefficient $\left(r_{s}\right)$ - to assess the strength of the identified relationship between variables; Student's t-test - to assess the essence of the identified relationship between the variables (the level of significance was considered significant $\mathrm{p}<0.05$ ). Statistical analysis was carried out using the statistical software package SPSS for Windows 11.0.

\section{Results}

According to various literary sources, an extremist's personality in terms of social behavior and interethnic communication is characterized by an increase in aggressive reactions (which are manifested in various types of aggression) against the background of low individualpersonal and socio-ethnic tolerance [19, 20, 21, 22, 23, 24].

To identify the distribution of aggression indicators and personality tolerance indices, the Ilyin scale of aggressive behavior was used, which allowed us to identify the level indicators of the severity of the corresponding variables.

Table 1. Distribution of indicators of severity of scales of aggression $(n=118)$.

\begin{tabular}{|c|l|c|c|c|c|c|c|c|c|}
\hline \multirow{2}{*}{$\begin{array}{c}\text { Severity levels of forms of } \\
\text { aggression }\end{array}$} & $\begin{array}{c}\text { Tendency to } \\
\text { direct } \\
\text { verbal } \\
\text { aggression }\end{array}$ & $\begin{array}{c}\text { Tendency to } \\
\text { indirect } \\
\text { verbal } \\
\text { aggression }\end{array}$ & $\begin{array}{c}\text { Tendency to } \\
\text { indirect } \\
\text { physical } \\
\text { aggression }\end{array}$ & $\begin{array}{c}\text { Tendency to } \\
\text { direct } \\
\text { physical } \\
\text { aggression }\end{array}$ \\
\cline { 3 - 12 } & Abs. & $\%$ & Abs. & $\%$ & Abs. & $\%$ & Abs. & $\%$ \\
\hline 1. & Low test rate & 31 & 26.3 & 43 & 36.4 & 44 & 37.3 & 41 & 34.7 \\
\hline 2. & Reduced test indicator & 42 & 35.6 & 37 & 31.4 & 38 & 32.2 & 27 & 22.9 \\
\hline 3. & Average test rate & 34 & 28.8 & 25 & 21.2 & 29 & 24.6 & 35 & 29.7 \\
\hline 4. & Increased test score & 10 & 8.5 & 12 & 10.2 & 7 & 5.9 & 11 & 9.3 \\
\hline 5. & High test rate & 1 & 0.8 & 1 & 0.8 & 0 & 0 & 4 & 3.4 \\
\hline
\end{tabular}


According to the frequency analysis, according to indicators of the severity of such forms of aggressive behavior as "tendency to indirect verbal aggression", "indirect physical aggression" and "direct physical aggression", only a third of the surveyed have low levels of severity $-36.4 \%, 37.3 \%$ and $34.7 \%$, respectively. In other cases, aggressive tendencies of varying degrees of severity are observed. Thus, $8.5 \%$ and $0.8 \%$ of respondents showed an increased and high level of direct verbal aggression, respectively. According to the propensity for indirect verbal aggression, $10.2 \%$ of respondents have an increased level of aggression, and $0.8 \%$ have a high level of aggression. $11 \%$ showed an increased level of propensity to physical aggression, while $4 \%$ of respondents have a high level of manifestation of this type of aggression. At the same time, the tendency to indirect physical aggression is at an increased level in 5.9\%, and a high level was not detected in any person.

Correlation analysis of the conjugacy of variables revealed the reliability of the relationship between variables

Table 2. Indicators of the conjugation of aggressive personal motives and parameters of ethno-social tolerance $(\mathrm{n}=118)$.

\begin{tabular}{|l|l|l|l|l|l|l|}
\hline \multicolumn{2}{|l|}{ Study variables } & & $\begin{array}{l}\text { The index of } \\
\text { xenophobia }\end{array}$ & $\begin{array}{l}\text { Subscale } \\
\text { "ethnic } \\
\text { tolerance }\end{array}$ & $\begin{array}{l}\text { Subscale } \\
\text { "social } \\
\text { tolerance" }\end{array}$ & $\begin{array}{l}\text { Subscale } \\
\text { "tolerance } \\
\text { as a } \\
\text { personality } \\
\text { trait" }\end{array}$ \\
\hline 1. & $\begin{array}{l}\text { Speed } \\
\text { information } \\
\text { processing }\end{array}$ & $\mathrm{r}_{\mathrm{s}}$ & .072 & -.046 & -.117 & $\mathbf{- . 2 2 0 *}$ \\
\hline 2. & $\begin{array}{l}\text { Lack of extensive } \\
\text { concentration }\end{array}$ & $\mathrm{r}_{\mathrm{s}}$ & .044 & $\mathbf{- . 1 7 7 ^ { * }}$ & $\mathbf{- . 2 6 2 * *}$ & -.117 \\
\hline 3. & $\begin{array}{l}\text { Linguistic } \\
\text { minimalism }\end{array}$ & $\mathrm{r}_{\mathrm{s}}$ & .080 & -.093 & -.114 & -.170 \\
\hline 4. & $\begin{array}{l}\text { Internet is the } \\
\text { main source of } \\
\text { information }\end{array}$ & $\mathrm{r}_{\mathrm{s}}$ & .059 & .003 & -.058 & -.115 \\
\hline 5. & $\begin{array}{l}\text { Rapid forgetting } \\
\text { of information }\end{array}$ & $\mathrm{r}_{\mathrm{s}}$ & .083 & -.038 & -.119 & $\mathbf{- . 2 0 6 *}$ \\
\hline
\end{tabular}

Note: rs- Spearman's rank correlation coefficient; ${ }^{*} \mathrm{p} \leq 0,05 ;{ }^{* *} \mathrm{p} \leq 0,01$.

As follows from the correlation matrix (table 2), the revealed correlations indicate that the subscale "Tolerance", as a personality trait, is negatively correlated with the variable of verbal aggression. Also, the "Ethnic tolerance" and "Social tolerance" subscales have negative relationships with certain types of aggressive reactions, which are simultaneously negatively associated with the individual's tendency to indirect verbal aggression. At the same time, the General index of personal aggression negatively correlates only with the subscale "Tolerance as a personality trait".

Thus, the revealed relationships allow us to state that the manifestation of certain aggressive reactions of the individual is accompanied by a decrease in tolerance to the social environment, and accordingly can become one of the triggers for the growth of general interpersonal and even interethnic tension, which in turn can be expressed in extremist forms of behavior of an individual prone to aggression. It is aggressive behavior that contributes to the rejection of the individual from society, his social isolation and inability to develop civilized forms of cooperation and general adaptation in society, followed by a person falling into certain anti-social extremes. 
Table 3. Level indices of xenophobia and tolerance indices severity $(n=118)$.

\begin{tabular}{|l|l|c|c|c|c|}
\hline \multirow{2}{*}{ Expressiveness of variables } & \multicolumn{2}{c|}{ Xenophobia Index } & \multicolumn{2}{c|}{ Tolerance index } \\
\cline { 3 - 6 } & Abs. & $\mathbf{\%}$ & Abs. & $\mathbf{\%}$ \\
\hline 1. & Low level & 50 & 42.4 & 0 & 0 \\
\hline 2. & Average level & 53 & 44.9 & 103 & 87.3 \\
\hline 3. & High level & 15 & 12.7 & 15 & 12.7 \\
\hline & Statistical significance & $\chi^{2}=22.695 ; \mathrm{p}=0.000$ & $\chi^{2}=65.627 ; \mathrm{p}=0.000$ \\
\hline
\end{tabular}

According to the data obtained (Table 3), the absolute majority of respondents are characterized by average indicators of the level of xenophobia severity $-44.9 \%$, a low level of xenophobia was found in $42.4 \%$ of those surveyed. At the same time, $12.7 \%$ of respondents have a high level, while the same number of surveyed have a high level of tolerance, while the absolute majority $(87.3 \%)$ is characterized by an average indicator of tolerance (low indicators of tolerance were not found in any respondent).

Analysis of the relationship between the forms of aggressive behavior with the parameters of the socio-psychological attitudes of the individual in the motivational-need-related sphere showed a significant dependence of various forms of motivational-need attitudes on the level of severity of aggression.

Table 4. Indicators of the conjugation of aggressive reactions with the parameters of the socio psychological attitudes of the personality in the motivational-need-related sphere, $(n=118)$.

\begin{tabular}{|l|l|l|c|c|c|c|}
\hline \multicolumn{2}{|c|}{ Study variables } & & Work orientation & $\begin{array}{c}\text { Freedom } \\
\text { orientatio } \\
\text { n }\end{array}$ & $\begin{array}{c}\text { Orientatio } \\
\text { n on } \\
\text { power }\end{array}$ & $\begin{array}{c}\text { Orientatio } \\
\text { n for } \\
\text { money }\end{array}$ \\
\hline 1. & $\begin{array}{l}\text { A tendency to } \\
\text { direct verbal } \\
\text { aggression }\end{array}$ & $r_{\mathrm{s}}$ & .127 & .108 & $.357^{* *}$ & $.258^{* *}$ \\
\hline 2. & $\begin{array}{l}\text { The tendency to } \\
\text { indirect verbal } \\
\text { aggression }\end{array}$ & $r_{\mathrm{s}}$ & -.029 & -.127 & .100 & $.351^{* *}$ \\
\hline 3. & $\begin{array}{l}\text { The tendency to } \\
\text { indirect physical } \\
\text { aggression }\end{array}$ & $\mathrm{r}_{\mathrm{s}}$ & .146 & .005 & $.206^{*}$ & $.194^{*}$ \\
\hline 4. & $\begin{array}{l}\text { Tendency to } \\
\text { direct physical } \\
\text { aggression }\end{array}$ & $\mathrm{r}_{\mathrm{s}}$ & .035 & .148 & $.206^{*}$ & .085 \\
\hline 5. & $\begin{array}{l}\text { General } \\
\text { aggression index }\end{array}$ & $\mathrm{r}_{\mathrm{s}}$ & .107 & .096 & $.294^{* *}$ & $.213^{*}$ \\
\hline
\end{tabular}

Note: $\mathrm{r}_{\mathrm{s}}$ - Spearman's rank correlation coefficient; ${ }^{*} \mathrm{p} \leq 0,05 ; * \mathrm{*} \leq 0,01$.

The data obtained show that practically all forms of aggressive behavior of a person are positively associated with such scales as "Power Orientation" and "Money Orientation". At the same time, the scales "Orientation to work" and "Orientation to freedom" are not characterized by the presence of significant correlations with one or another form of aggressive behavior.

The conjugation of the aggressive impulses of the individual and his motivational attitudes in the field of achieving power and material wealth (money) is perhaps one of the most important mechanisms for self-realization of an extremist-minded personality. In this case, it is safe to say that the motivated movement of an individual in the direction of achieving power or material resources will be accompanied by the manifestation of aggression and violence against objects that hinder the achievement of the goal (these objects can be certain institutions of power, society, etc.), which in turn can cause extreme extremist forms of manifestation of internal impulses aimed at achieving power and material resources when a state of frustration occurs in the subject of aggressive behavior. 
At the same time, the data obtained indicate that the predominance of power orientations in the motivational-need-related sphere of the individual is accompanied by an increase in the individual's propensity to direct verbal, indirect physical and direct physical types of aggression. Whereas the predominance of money orientations in the motivational-needrelated sphere is associated with the individual's tendency to direct verbal, indirect verbal and indirect physical forms of aggressive behavior. Both power orientation and money orientation are associated with an increase in the overall index of aggressive behavior of the individual. At the same time, only money orientation is positively associated with the individual's tendency to direct physical aggression.

According to the data obtained, the forms of aggressive behavior identified in respondents for the most part do not have any significant relationships with intense stressful experiences manifested in the form of post-traumatic stress reactions, with the exception of the individual's tendency to indirect verbal aggression, which simultaneously positively correlates with all scales of the assessment scale the impact of the traumatic event. Thus, the identified relationships indicate that the propensity to indirect verbal aggression may be accompanied by an increase in post-traumatic symptoms and vice versa.

Table 5. Indicators of the conjugation of types of aggressive behavior and intense stressful experiences caused by traumatic events $(n=118)$.

\begin{tabular}{|l|l|l|c|c|c|c|}
\hline \multicolumn{2}{|c|}{ Study variables } & & Invasion & $\begin{array}{c}\text { Avoidanc } \\
\text { e }\end{array}$ & $\begin{array}{c}\text { Physiologica } \\
\text { l excitability }\end{array}$ & PTS Index \\
\hline 1. & $\begin{array}{l}\text { A tendency to } \\
\text { direct verbal } \\
\text { aggression }\end{array}$ & $r_{\mathrm{s}}$ & .055 & .059 & .173 & .100 \\
\hline 2. & $\begin{array}{l}\text { The tendency to } \\
\text { indirect verbal } \\
\text { aggression }\end{array}$ & $\mathrm{r}_{\mathrm{s}}$ & $\mathbf{. 1 8 5 ^ { * }}$ & $\mathbf{. 2 7 9 * *}$ & $\mathbf{. 2 2 7 * *}$ & $\mathbf{. 2 4 2 * *}$ \\
\hline 3. & $\begin{array}{l}\text { The tendency to } \\
\text { indirect physical } \\
\text { aggression }\end{array}$ & $\mathrm{r}_{\mathrm{s}}$ & .017 & .057 & .081 & .047 \\
\hline 4. & $\begin{array}{l}\text { Tendency to } \\
\text { direct physical } \\
\text { aggression }\end{array}$ & $\mathrm{r}_{\mathrm{s}}$ & -.104 & -.153 & -.050 & -.110 \\
\hline 5. & $\begin{array}{l}\text { General } \\
\text { aggression index }\end{array}$ & $\mathrm{r}_{\mathrm{s}}$ & -.009 & -.020 & .094 & .017 \\
\hline
\end{tabular}

Note: $\mathrm{r}_{\mathrm{s}}$ - Spearman's rank correlation coefficient; $* \mathrm{p} \leq 0,05 ; * * \mathrm{p} \leq 0,01$

Experiencing a traumatic event accompanied by the development of intense posttraumatic stress reactions also determines the individual's demonstration of indirect verbal aggression, which in turn can also affect the experience of the relationship of the traumatized person with the closest social environment, which is confirmed by previous studies conducted among the population of the Chechen Republic, in which it has been reliably established that the development of aggressive impulses of the personality is positively associated with the experiences of intense stress reactions of a post-traumatic nature, which also correlate with character accentuations, including also features of aggressive-destructive dispositions [25, $26,27]$.

\section{Conclusions}

1. It is established that aggressive forms of individual behavior are accompanied by an increase in the overall level of social tolerance, which in turn can become one of the factors of increasing tension in society, disrespect and intolerance towards others, including people of other nationalities and faiths. 
2. The presence of traumatic experiences deepens and intensifies aggressive forms of behavior, forming indirect verbal aggression, leading to the disintegration of the individual with the microsocial environment and socio-psychological maladjustment.

3. Various forms of aggressive behavior are positively associated with such motivational attitudes of the individual as an orientation toward power and toward money. At the same time, the predominance of orientations towards power in the motivational-need-related sphere of the individual is accompanied by an increase in the indicators of the individual's propensity to direct verbal, indirect physical and direct physical types of aggression. And the orientation towards money is positively correlated with the manifestation of a tendency to direct verbal, indirect verbal and indirect physical impulses of an aggressive nature.

\section{References}

1. M.K. Archakov, Political extremism: essence, manifestations, countermeasures: monograph (Yurayt Publishing House, M., 2020)

2. O.A. Rusanova, Vestnik Mosk. un-that. Ser. 18: Sociology and Political Science 2, 117 (2005)

3. S.N. Fridinsky, Combating extremism: criminal law and criminological aspects (Rostov-on-Don, 2004)

4. D.S. Beznosov, L.G. Pochebut, Bulletin of St. Petersburg State University. Series 12. Sociology 1 (2010)

5. A.V. Martynenko, Prevention of extremism among youth: a textbook for universities (Yurayt Publishing House, M., 2020)

6. L.I. Bochantseva, M.A. Gorodilova, Problems of modern education 5, 48-62 (2019)

7. K. Lorenz, Aggression, or the so-called evil (AST, M., 2017)

8. Z. Freud, Introduction to psychoanalysis. Lectures (M., 2007)

9. N.V. Prokazina, A.V. Isaev, Bulletin of the Volga Institute of Management 2(47), 31-36 (2015)

10. N.V. Prokazina, Bulletin of the Volga Institute of Management 2(53), 114-121 (2016)

11. V.V. Kostenko, Srednerusskiy Vestnik of Social Sciences 3, 82-90 (2014)

12. D.V. Olshansky, Psychology of terrorism (Peter, SPb, 2002)

13. L.M. Drobizheva, Social problems of interethnic relations in post-Soviet Russia (Zh. Center for Human Values, M., 2003)

14. N.V. Tarabrina, A Practical Guide to the Psychology of Post-Traumatic Stress. At 2CH. Part 2. Method forms ("Kogito-Center", M., 2007)

15. G.U. Soldatova, O.A. Kravtsova, O.E. Khulaev et al, Inf. - analyte bulletin 4, 59-65 (2002)

16. Methods of psychological diagnostics of aggression and aggressiveness of schoolchildren: Teaching aid (Saratov, 2016)

17. E.N. Yurasova, Legal Psychology 4, 27-35 (2008)

18. Practical psychodiagnostics. Techniques and tests. Textbook (Samara, 2001)

19. Yu.M. Antonyan, Extremism and its causes (Logos, M., 2010)

20. A.E. Semyonov, V.V. Tikhonov, Youth environment - a territory without extremism: materials region. stud. scientific-practical conf. (Publishing house of ANSTU, Angarsk, 2018)

21. V.D. Khromov, Obzor. NTSPTI 4(15), 65-77 (2018) 
22. J. Međedović, G. Knezevic, Journal of Individual Differences (2018) DOI: 10.1027 / 1614-0001 / a000280

23. A. Merari, Driven to Death. Psychological and Social Aspects of Suicide Terrorism (Oxford University Press, Oxford, 2010)

24. J. Post, K. Ruby, E. Shaw, The Radical Group in Context: 1. An Integrated Fr

25. A.A. Saidov, I.S. Khazhuev, Problems of modern pedagogical education 66-4, 340-345 (2020)

26. I.S. Khazhuev, Human capital 9(105), 58-61 (2017)

27. I.S. Khazhuev, A.A. Saidov, Problems of modern pedagogical education 66-4, 363-367 (2020) 